Article

\title{
Evaluation of Lipases from Wild Microbial Strains as Biocatalysts in Biodiesel Production
}

\author{
Carlos Luna ${ }^{1}\left(\mathbb{D}\right.$, Diego Luna ${ }^{1, *} \mathbb{\infty}$, Felipa M. Bautista ${ }^{1}$, Juan Calero ${ }^{1}$, Antonio A. Romero ${ }^{1}$, \\ Alejandro Posadillo ${ }^{2}$, Enrique D. Sancho ${ }^{3}$ and Rafael Estevez ${ }^{1}$ \\ 1 Departamento de Química Orgánica, Universidad de Córdoba, Campus de Rabanales, Ed. Marie Curie, \\ 14014 Córdoba, Spain; qo2luduc@uco.es (C.L.); qo1baruf@uco.es (F.M.B.); p72camaj@uco.es (J.C.); \\ qo1rorea@uco.es (A.A.R.); q72estor@uco.es (R.E.) \\ 2 Seneca Green Catalyst S.L., Campus de Rabanales, 14014 Córdoba, Spain; seneca@uco.es \\ 3 Departamento de Microbiología, Universidad de Córdoba, Campus de Rabanales, Ed. Marie Curie, \\ 14014 Córdoba, Spain; mi1sapue@uco.es \\ * Correspondence: qo1lumad@uco.es; Tel.: +34-957-21-2065
}

Received: 9 October 2018; Accepted: 1 November 2018; Published: 5 November 2018

\begin{abstract}
In this study, the evaluation of the catalytic behavior of several wild bacterial strains in the 1,3-selective ethanolysis of triglycerides with ethanol to produce a new type of biodiesel (Ecodiesel) that integrates glycerol as monoacylglycerols was carried out. The Ecodiesel production not only avoids the elimination of glycerol, which is largely generated as a by-product in the biodiesel industry, but also results in an increase in the biofuel yield. The wild microbial strain samples were obtained from several lipophilic organisms. In addition to evaluate the enzymatic extracts, the minimum grade of purification of the strains, necessary to obtain similar results to those attained with commercial lipases was studied. This purification treatment included a dialysis followed by a lyophilization process. Such extracts were directly used as biocatalysts in the transesterification reaction of sunflower oil with ethanol, attaining much better results (yield close to 100\%) than those obtained with strains which were not submitted to the purification process (yields lower than $10 \%$ ). Furthermore, the results here obtained are similar to those obtained with commercial lipases but were achieved under mild conditions and lower reaction time $(2 \mathrm{~h})$. In addition, the stability of the enzymatic extracts was corroborated by subsequent reactions, showing no loss of activity. Thus, this study brings to light that enzymatic extracts obtained by a very simple purification process can be economically competitive with the conventional biodiesel production methods.
\end{abstract}

Keywords: biodiesel; ethanolysis; wild microbial lipase; transesterification; Ecodiesel; sunflower oil

\section{Introduction}

The evaluation of alternative energies which can substitute the non-renewable ones (natural gas, coal, and fossil fuels) for electricity generation is a growing trend for reasons associated with environmental preservation [1,2]. However, there is no such equivalent in the transport sector. To date, electric motors as well as vehicles capable of using fuel cells are not able to compete with explosion or combustion engines, especially in the aviation field [3]. Thus, the search of renewable materials capable of replacing fossil fuels and that allow working with the current engines without any modifications seems to be essential [4].

At present, the only renewable materials considered for the substitution of diesel fuel are vegetable oils or animal fats used as biofuel, and the main existing technology to obtain biodiesel is based on the transesterification of triglycerides with methanol to obtain fatty acids methyl esters (FAME). Different alternative processes have been proposed, such as dilution of the vegetable oils, emulsification, 
pyrolysis, and hydrotreating [5]. However, nowadays, the industrial production of biodiesel is carried out by homogeneous alkali-catalyzed transesterification of vegetable oils with methanol [1]. After the reaction, biodiesel is recovered by repeated washing with water to remove glycerol, soap, and excess methanol [5-7]. Nevertheless, the generation of glycerol as a byproduct is a major issue, because a high amount of water must be employed to remove it. In fact, this is one of the main difficulties associated with biodiesel production in many regions where water is not abundant, such as the Mediterranean countries [6].

In this sense, different methods to obtain glycerol derivatives during the transesterification process preventing waste generation have been considered. Furthermore, the glycerol derivatives would allow to increase the yield of the process (always higher than the nominal 10\%), as some of this glycerol is integrated in the reaction products. These alternative methodologies to prepare esters from lipids using different acyl acceptors are still under development [8]. The transesterification reaction of triacylglycerols with dimethyl carbonate (DMC) [9], methyl acetate [10], or ethyl acetate [11] could generate a mixture of three molecules of FAME or FAEE (fatty acid ethyl ester) and one of glycerol carbonate or glycerol triacetate (triacetin). These mixtures that integrate glycerol derivative molecules exhibit relevant physicochemical properties for being employed as novel biofuels [9-12], because the glycerol derivatives possess rheological properties close or similar to those of FAME or FAEE, while containing a higher amount of oxygen and thus reducing the pollutants produced during the combustion.

In this regard, we have recently succeeded in the preparation of a new type of biodiesel that integrates glycerol into their composition via 1,3-regiospecific enzymatic transesterification of sunflower oil, using free $[13,14]$ and immobilized porcine pancreatic lipase (PPL) [15]. Thus, the already patented Ecodiesel integrates glycerol as a derivative product in the diesel fuel, with the advantage that dimethyl carbonate or methyl acetate, more expensive than methanol or ethanol, are not employed (in contrast with other reported strategies). The procedure employed takes advantage of the 1,3-selective nature of lipases, which allows to "stop" the process in the second step of alcoholysis, obtaining a mixture of two moles of FAEE and one of monoacylglycerols (MG), as can be seen in Figure 1.

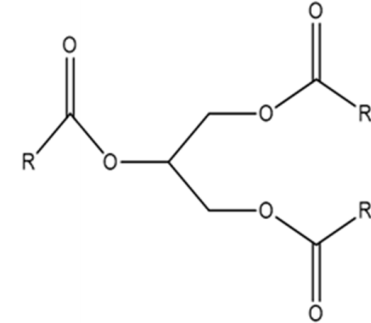

Triglyceride

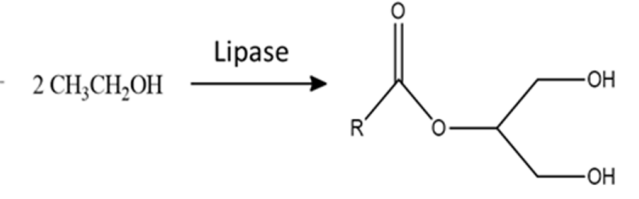

Ethanol
Monoglyceride

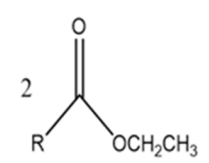

FAEE

Figure 1. Reaction scheme of the 1,3-selective enzymatic catalysis to produce Ecodiesel, a biodiesel-like biofuel.

In comparison with the conventional method, the experimental conditions for Ecodiesel production are much smoother, the removal of impurities is unnecessary, and the biofuel produced exhibits similar physicochemical properties to the conventional biodiesel. Furthermore, MG enhance biodiesel lubricity, as it has been demonstrated in recent researches [16-18]. Besides, as ethanol is in excess, there is some amount of it in the product blend, allowing its direct employment as a fuel. Thus, the term Ecodiesel is ascribed to any blend of fatty acid alkyl esters with ethanol, alone or with any proportion of diesel fuel [19-23].

Initially, Ecodiesel was obtained by using PPL. Remarkable results were also attained with the microbial lipase Lipopan 50 BG (Novozymes AS, Denmark) [7,14], a low-cost purified lipase from the microorganism Thermomyces lanuginosus, usually employed as a bread emulsifier (bread improver) [24] and never previously described as a biocatalyst in chemical processes. Similarly, the enzymatic 
ethanolysis of sunflower oil with ethanol, in free solvent media, has been studied in the presence of different lipases as well [25]. Likewise, Rhizopus oryzae lipase, from Biolipase-R, immobilized on Sepiolite, an inorganic support, was also studied to get the economic viability of the procedure [26]. In fact, the application of an available lipase on an industrial scale is a significant step towards the economic feasibility of biofuel production by an enzymatic method, because the high production costs of lipases is actually the main drawback in the application of this procedure.

In a recent work, some microbial lipases, from several wild microorganism strains selected in several lipophilic microorganisms such as olive oil press, animal fats, etc., have been also selected in order to improve the viability and competitiveness of the enzymatic process [27]. In that study, the selected strains belonged to the genera Pseudomonas, Acinetobacter, Enterobacter, Bacillus, and Terribacillus, and the best results were attained on a gram-positive bacterium belonging to the genus Terribacillus (OS-2) (yield $>80 \%$ ), which had not been previously reported as a biofuel producer. Thus, these new microorganisms and their lipolytic enzymes can open a window of possibilities for synthetic processes, because enzymatic extracts can be easily obtained, reducing the cost of enzyme production in a notable way and, therefore, producing the biofuel in a cheaper way.

These previous researches demonstrated that it is possible to operate with non-excessively purified enzymatic extracts in order to achieve the partial transesterification process of the triglycerides with a high performance $[27,28]$. It is evident that the presence of other enzymes does not modify the lipases activity, because of the absence of their corresponding substrates. Therefore, we assumed a new paradigm, that is, to operate with very little purified enzymatic extracts of lipases. Thus, in the present study, we tried to determine the minimum purification degree of some wild microbial strains, previously described, necessary to get lipases which can be efficient in the 1,3-selective ethanolysis process. Thereby, we would be able to considerably reduce the production costs, making the production of alternative biofuels technically and economically viable.

\section{Materials and Methods}

\subsection{Chemicals}

Commercial sunflower oil was obtained from the local region. The ethyl esters of palmitic acid, stearic acid, oleic acid, linoleic acid, and linolenic acid were from Accustandard, and methyl heptadecanoate was from Sigma-Aldrich; all of them were chromatographically pure. Other chemicals, like absolute ethanol and sodium hydroxide ( $>99 \%$ of purity), were from Panreac Química SLU, Castellar del Vallès (Barcelona) Spain.

\subsection{Collection, Isolation, and Screening of Lipolytic Microorganisms Able to Carry out the Transesterification Reaction}

The wild-type microorganisms used in this study were obtained from a previous selection made among a thousand samples of vegetable oils (OS) supplied by an olive oil mill located in Seville, (Spain) and from animal fats (FS) from sawdust of fish (FS1) obtained in Cadiz (Spain) [27]. The samples were evaluated in a preliminary screening by a qualitative plate assay to select the microorganisms showing lipolytic activity. In a second step, the lipolytic bacteria were analyzed using a colorimetric assay to detect transesterification activity. This method consists in the transesterification of para-nitrophenyl palmitate (p-NPP) with ethanol in the absence of water to release the yellow-colored compound para-nitrophenol (p-NP), which can be subsequently detected by using a spectrophotometer. Thus, all positive hydrolytic microorganisms were grown in a typical liquid medium for bacteria with $2 \%$ tributyrin for 3 days at $30^{\circ} \mathrm{C}$ and then centrifuged. The supernatants were freeze-dried for $24 \mathrm{~h}$ and mixed with $1 \mathrm{~mL}$ of $10 \mathrm{mM}$ p-NPP (in n-hexane) and $60 \mu \mathrm{L}$ of absolute ethanol. These mixtures were incubated at $37^{\circ} \mathrm{C}$ with shaking for $16 \mathrm{~h}$. A negative control was obtained by using a mixture of absolute ethanol and p-NPP. The mixture of p-NPP and freeze-dried supernatant (without ethanol) was used as a control of the hydrolytic activity of lipases. Thirty of the best lipolytic strains were selected 
for further characterization. Phylogenetic analysis was performed through a16S rRNA sequences of bacteria with neighbor-joining clustering, revealing that 23 of the bacterial isolates were Gram-negative and 7 were Gram-positive, belonging to different clades. The bacterial strains previously selected were grown for 3 days. The growth media were liquids in the form of broth. After the preparation, they were conveniently sterilized in autoclave at a temperature of $121^{\circ} \mathrm{C}$ for $20 \mathrm{~min}$. The broth media were prepared and stored in Pyrex containers for storage or in flasks $(500 \mathrm{~mL})$ for the growth of the strains (100 mL medium). Then, $25 \mathrm{~mL}$ of culture supernatants was concentrated by dialysis (12 KDa) and lyophilized for $48 \mathrm{~h}$ to obtain an extract $(0.5 \mathrm{~g})$ in the form of fine dry powder which could be used directly as a biocatalyst in the production of biofuels by sunflower oil ethanolysis [27].

\subsection{Ethanolysis Reactions}

These reactions were performed according to the procedure previously described [14-18,28-31]. A preceding study to determine the optimal experimental conditions of the reaction was carried out with a commercial low-cost lipase, Lipopan BG (Novozymes AS, Denmark), which then served as a reference for the expected variability in lipases extracts from wild microbial strains $[14,15,26]$.

To determine the efficiency of the wild enzymatic systems, the assays were carried out applying the optimum conditions predetermined by the addition of $6 \mathrm{~mL}$ of commercial sunflower oil, $1.75 \mathrm{~mL}$ of absolute ethanol, and $12.5 \mu \mathrm{L}$ of $10 \mathrm{~N} \mathrm{NaOH}$ into a $20 \mathrm{~mL}$ tube containing the enzyme extract of the corresponding wild microorganism strain to be tested. The transesterification reactions were carried out directly in the same sterile plastic tube used for enzymatic extraction. So, after adding the reagents and a small magnetic stirrer, the tube was introduced for $24 \mathrm{~h}$ in a water bath at $30^{\circ} \mathrm{C}$, with stirring higher than $300 \mathrm{rpm}$. Less than $10 \%$ conversion of the starting material was found under these conditions without any lipase, so that a blank contribution can be considered as negligible under the current investigated conditions. For all experiments, a minimum of three replicates were carried out in order to see the reproducibility of the procedure. The standard deviation was always lower than $6 \%$.

Reusability studies were performed with eight selected enzymatic extracts, operating under the same standard experimental conditions. The reaction products were extracted each time, then we left the previously used extract in the bottom of the tube and we added the reagents to generate a new reaction cycle.

\subsection{Analytical Method}

The reaction products were monitored by gas chromatography (GC), using a Varian 430-GC gas chromatograph (Europe, 4330 EA Middelburg, The Netherlands), equipped with a HT5 capillary column $(25 \mathrm{~m} \times 0.32 \mathrm{~mm}$ ID $\times 0.1 \mu \mathrm{m}$, SGE, Supelco, Sigma-Aldrich Quimica SL, Madrid, Spain $)$ and a FID detector at $450{ }^{\circ} \mathrm{C}$ and splitless injection at $350^{\circ} \mathrm{C}$. The analysis program employed was the same as that used elsewhere, using n-hexadecane (cetane) as an internal standard to quantify the content of ethyl esters and glycerols (mono-, di-, and triacylglycerols) with the help of some commercial fatty acid esters standard [13-15,25,27].

Considering that sunflower oil is constituted by a mixture of fatty acids in variable proportion (mainly linoleic, oleic, palmitic, and stearic acids), the reactions results were expressed as the relative amounts of the corresponding ethyl esters (FAEE), MG, and diacylglycerols (DG) that were integrated in the chromatogram. By difference and with respect to the internal standard (cetane), the amount of triacylglycerols (TG) which did not react was calculated in mass percentage. The conversion included the total amount of triacylglycerols transformed (FAEE + MG + DG) in the ethanolysis process, and selectivity referred to the relative amount of FAEE + MG obtained, which presented lower retention times (RT) than those hydrocarbons that compose fossil diesel (RT $<26 \mathrm{~min}$ ). 


\subsection{Viscosity Measurements}

The transesterification reactions of oils or fats was carried out to obtain an important reduction in viscosity, as they share similar other physicochemical parameters to the fossil diesel, except for viscosity, which has values in the range of $30-45 \mathrm{~mm}^{2} / \mathrm{s}$ (or cSt), while fossil diesel exhibits values in the range of 2.5-6 cSt. Because of the importance of viscosity for the correct running of diesel engines, this parameter becomes a critical factor that has to be modified before vegetable oils can be used as biofuel. Thus, accurate viscosity measurements are critical to assess the quality of biofuels produced. Viscosity was determined in a capillary viscometer Oswald Proton Cannon Fenske Routine Viscometer 33200, size 150 Sigma Aldrich, Spain [14-18,28-31].

\section{Results and Discussion}

\subsection{Comparative Chromatograms of Standardized Reaction Products}

Figure 2a shows the most characteristic biofuels components, obtained by enzymatic alcoholysis. Furthermore, a representative sample of monoglycerides of sunflower oil, which was easily obtained by the substitution of methanol or ethanol for glycerol in a conventional alcoholysis process in the same experimental conditions, is also shown.

a)

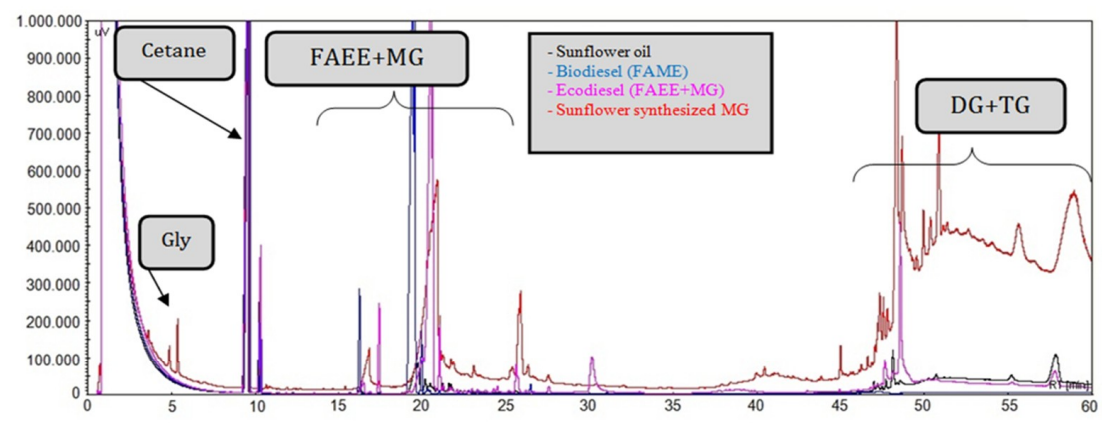

b)

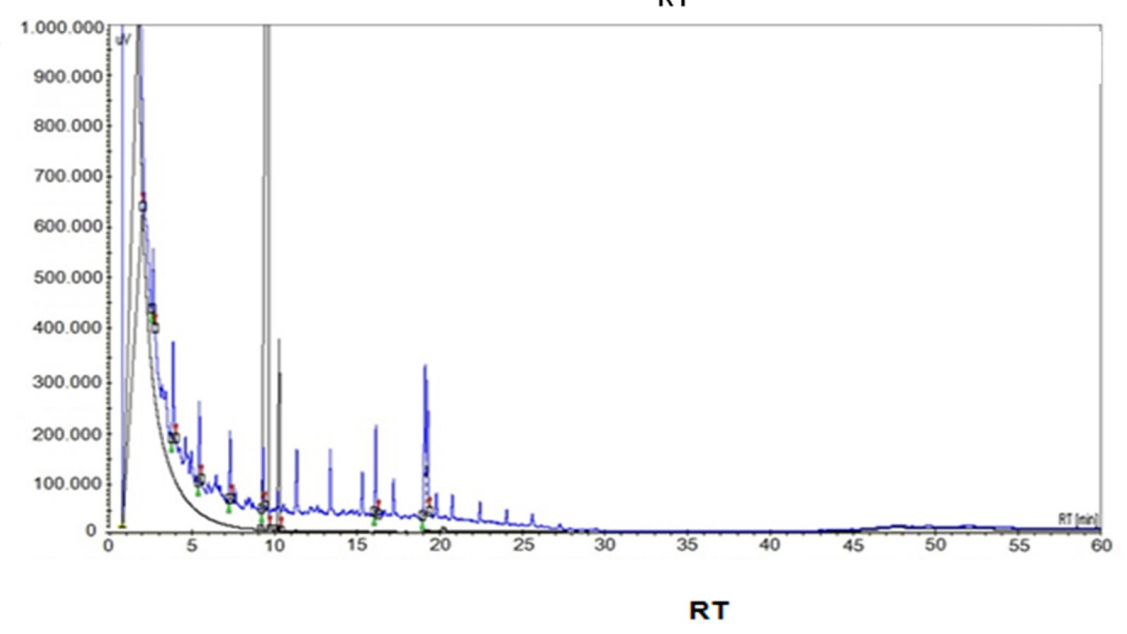

Figure 2. (a) Chromatograms related to the alcoholysis of sunflower oil with methanol over OS2; Fatty Acid Methyl Esters (FAME), ethanol, Fatty Acid Ethyl Esters (FAEE), glycerol (gly), monoacylglycerols (MG), diacylglycerols (DG), triacylglycerols (TG), and the initial sunflower oil are plotted in blue, pink, red, and black, respectively. (b) Commercial diesel fuel chromatogram.

The fatty acid esters (FAE), which constitute the lipid profile of the sunflower oil, displayed RT slightly higher (16-26 $\mathrm{min}$ ) than cetane (10 $\mathrm{min})$. The lipid profile included methyl, ethyl, and glycerol esters (the latter were MGs) of palmitic, stearic, linoleic, and oleic acids. Among them, palmitic acid derivatives (C16: 0) were grouped in a narrow RT range, 16-17 min, and oleic and linoleic acid 
(C18: 1) derivatives were grouped between 19 and 21 min, except for oleic acid MG, which presented a different behavior, with RT $=26 \mathrm{~min}$. Besides, glycerol RT was $5 \mathrm{~min}$. The absence of this compound in the chromatograms brought to light the selectivity of the enzymatic transesterification reaction. Furthermore, the presence of DG, (RT of 40-60 min) can be also observed in Figure 2a. To determine the DG + TG amount, the use of an internal standard (cetane) was required because of the difficulty in peaks integration. On the other hand, the FAMEs, FAEEs, and MGs displayed slightly higher RT values than cetane, but within the molecular weight range, which suggested similar chemical-physical properties between the FAE and the hydrocarbons constituting the diesel, according to Figure $2 \mathrm{~b}$.

In fact, considering the chromatogram obtained for a diesel fuel (Figure $2 b$ ), we determined that it consisted of a complex mixture of hydrocarbons that appeared at RT in the range of that of the cetane. As it is well known, cetane is considered the "standard fuel" for internal combustion engines or diesel engines, so its "index" (in percentage form) is employed for checking the quality of fuels.

It is important to mention that, whereas the conversion values include of FAEE + MG obtained, which presented lower RT than those hydrocarbons forming part of fossil diesel the amount of triacylglycerols produced (FAEE + MG + DG), the selectivity refers to the amount (RT $<26 \mathrm{~min}$ ). This implies that a high conversion, even $100 \%$, could contain a high proportion of DG molecules, with high molecular weight and viscosity values. Consequently, a very high selectivity, i.e., a very high percentage of FAEEs and MGs, could promote a viscosity close to that of petroleum diesel; therefore, complete conversion is not a guaranty of low viscosity values.

\subsection{Ethanolysis Reactions}

In previous researches, the optimal experimental conditions of the ethanolysis reaction, using a purified lipase from T. lanuginosus, Lipopan 50 BG (Novozymes AS, Denmark), as a catalyst, were obtained [14,24]. Therefore, these results were employed as a reference when examining the expected variability for lipases from wild microbial strains. The wild-type microorganisms employed in this research were obtained from a previous selection among a thousand of samples, from both OS and FS [27], belonging to the genera Pseudomonas, Acinetobacter, Enterobacter, Bacillus, and Terribacillus, as indicated in the Introduction section. Once the bacterial strains were selected, they were grown for three days in their corresponding optimal broths cultures. Then, $25 \mathrm{~mL}$ of culture supernatants, containing extracellular lipases, was concentrated by dialysis (12 KDa) and lyophilized for $48 \mathrm{~h}$ to obtain an extract $(0.5 \mathrm{~g})$ in the form of fine dry powder which could be used directly as a biocatalyst in the production of biofuels by sunflower oil ethanolysis $[27,28]$. Thus, the catalytic behavior of the enzymatic extracts of the corresponding wild microorganism strains could be related to the amount and to the efficiency of the commercial lipases, taking into account that all the extracts $(0.5 \mathrm{~g}$ fine dry powder) could contain a similar quantity of lipases, according to the identical procedure of extraction applied in each of them. Therefore, the different results obtained in the alcoholysis reaction could be ascribed to the variation in the efficiency of the lipase. As can be seen in Table 1, there was a wide range of lipase concentration in which the enzymatic activity was maintained. Thus, the results obtained with the wild microorganism strains extracts could be related to the quality of the lipases present in the enzymatic extracts.

Table 1. Influence of the amount of Lipopan BG (Novozymes AS, Denmark) in the ethanolysis reaction performance, developed under standard conditions; fatty acid esters (FAE).

\begin{tabular}{cccccc}
\hline Lipase Amount (g) & Conversion (wt \%) & FAE (wt \%) & DG (wt \%) & TG (wt \%) & Viscosity (cSt) \\
\hline 0.007 & 85.7 & 77.9 & 7.9 & 14.3 & 9.4 \\
0.010 & 100 & 96.1 & 3.9 & 0.0 & 10.1 \\
0.020 & 100 & 97.9 & 2.1 & 0.0 & 9.8 \\
0.030 & 90.2 & 90.0 & 0.1 & 10.0 & 11.5 \\
0.040 & 100 & 98.0 & 2.0 & 0.0 & 10.7 \\
\hline
\end{tabular}

(a) Standard condition: $6 \mathrm{~mL}$ of sunflower oil, $1.75 \mathrm{~mL}$ of absolute ethanol, and $12.5 \mu \mathrm{L}$ of $10 \mathrm{~N} \mathrm{NaOH}, 300 \mathrm{rpm}$ stirring, at $30^{\circ} \mathrm{C}$ for $24 \mathrm{~h}$ and varying lipase amounts. 
As aforementioned, the evaluation of the purification degree of the lipases extracts is mandatory for reducing the catalyst cost. In this sense, every lipase extract was directly used as a biocatalyst in the transesterification reaction of sunflower oil with absolute ethanol after a simple lyophilization process and an additional treatment, consisting in a dialysis process followed by filtration and pre-concentration of the extracts.

The efficiency of those extracts obtained by only a lyophilization treatment, without applying a previous dialysis, was negligible, since low yield were obtained (0-10\%), Figures 3 and 4 . However, after subjecting the same strain extracts to the additional treatment, the yield considerably increased, indicating the importance of the second step.
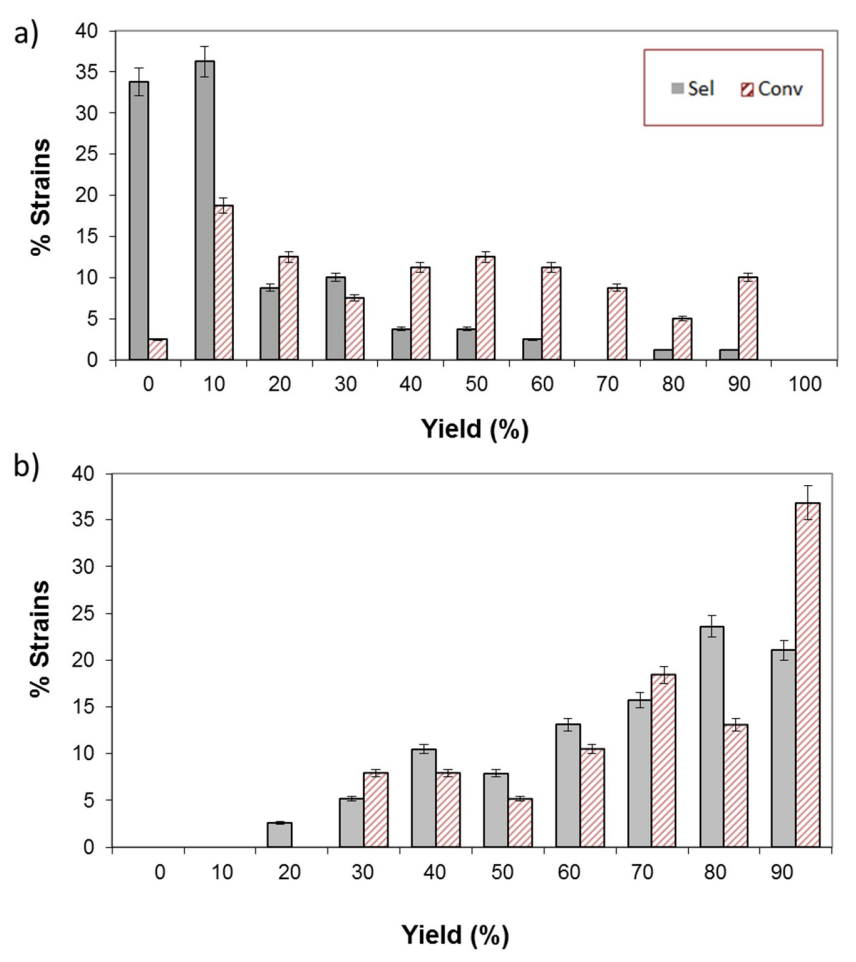

Figure 3. (a) Comparison of the catalytic performance of sawdust of fish (FS1) (percentage of studied strains that present a determined range of yield percentage) in the ethanolysis reaction of the totality of freeze-dried-lyophilized extracts without previous dialysis; (b) the same as (a) but after a simple previous dialysis treatment, under the same standard experimental conditions. Selectivity (Sel, \%) is presented in grey, and conversion (Conv, \%) in pink lines.

This simple methodology allowed us to access to the enzymatic material, which met the minimum requirements for performing the enzymatic alcoholysis process, in a simple and inexpensive way, in comparison to the commercial purified lipases, e.g., Lipopan 50 BG (Novozymes AS, Denmark).

The results obtained in the enzymatic ethanolysis of sunflower oil are collected in Table 2. In general, these results obtained with the enzymatic materials are quite similar to those obtained on commercial lipases, Table 1. The samples obtained from OS, i.e., OS-3, OS-4, OS-5, OS-6, OS-8, OS-10, OS-15, OS-19, and those obtained from FS, e.g., FS-4, exhibited conversion and selectivity values in the percentage ranges of $60-100 \%$, respectively, which allowed to obtain viscosity values lower than $11.5 \mathrm{cSt}$. Taking into account that around $0.5 \mathrm{~g}$ of these materials was able to perform an enzymatic activity similar to that of $0.01-0.04 \mathrm{~g}$ of an expensive commercial lipase, the economic viability of the process must be highlighted. On the other hand, comparing the efficacy of the isolated extracts from vegetal oils with those from animal fats of all the studied strains, it could be affirmed that the extracts from animal fats had an acceptable overall performance, although inferior to that of extracts obtained 
from vegetable oils. Among the animal fat samples, strains from FS1 presented much better yields than strains from ham fat (FS2).

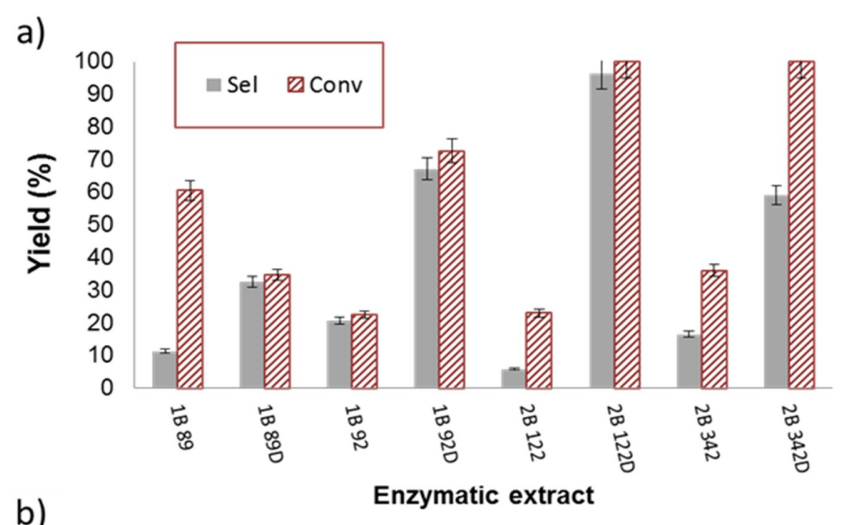

b)

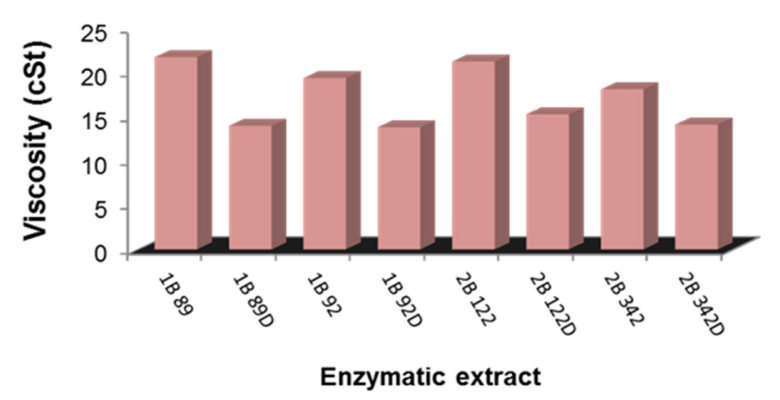

Figure 4. Comparison of the catalytic performance (a) and viscosity in cSt (b) obtained in the ethanolysis reaction over some cultured microbial wild strains either submitted to the dialysis treatment or not.

Table 2. Conversion, selectivity, and viscosity obtained in the enzymatic ethanolysis of sunflower oil under different lyophilized bacterial extracts, with previous dialysis, from vegetable oil (OS) and animal fat (FS) samples. Reaction conditions: $37^{\circ} \mathrm{C}, 24 \mathrm{~h}, 300 \mathrm{rpm}$, operating with $6 \mathrm{~mL}$ of oil, $1.75 \mathrm{~mL}$ of absolute ethanol, and $0.0125 \mathrm{~mL}$ of $10 \mathrm{~N} \mathrm{NaOH}$ solution. Conversion = FAE + DG, being $\mathrm{FAE}=(\mathrm{FAEE}+\mathrm{MG})$ the selectivity of the process. A minimum of three replicates for each experiment were carried out (less than $6 \%$ of error was obtained).

\begin{tabular}{cccccc}
\hline SAMPLE & Conversion $\mathbf{( w t}$ \%) & FAE (wt $\%)$ & DG $\mathbf{( w t}$ \%) & TG (wt \%) & Viscosity (cSt) \\
\hline OS 1 & 69.8 & 63.1 & 6.7 & 30.2 & 11.7 \\
OS 2 & 100.0 & 93.7 & 6.3 & 0.0 & 11.8 \\
OS 3 & 68.4 & 65.9 & 2.5 & 31.7 & 10.9 \\
OS 4 & 92.9 & 80.1 & 12.9 & 7.1 & 10.8 \\
OS 5 & 61.8 & 58.7 & 3.1 & 38.2 & 11.4 \\
OS 6 & 69.8 & 67.4 & 2.5 & 30.2 & 11.3 \\
OS 7 & 83.8 & 72.2 & 11.6 & 16.2 & 15.0 \\
OS 8 & 87.6 & 80.1 & 7.5 & 12.4 & 11.7 \\
OS 9 & 83.8 & 76.0 & 7.8 & 16.2 & 12.4 \\
OS 10 & 71.9 & 66.8 & 5.1 & 28.1 & 10.8 \\
OS 11 & 89.3 & 87.6 & 1.8 & 10.7 & 13.2 \\
OS 12 & 79.9 & 71.8 & 8.1 & 20.1 & 13.7 \\
OS 13 & 87.1 & 77.5 & 3.2 & 12.9 & 11.7 \\
OS 14 & 48.8 & 48.1 & 0.7 & 51.2 & 11.9 \\
OS 15 & 90.4 & 82.6 & 7.8 & 9.6 & 11.2 \\
OS 16 & 59.8 & 49.3 & 10.5 & 40.2 & 12.2 \\
OS 17 & 54.7 & 54.0 & 0.7 & 45.4 & 12.0 \\
OS 18 & 100 & 59.1 & 41.0 & 0 & 13.1 \\
OS 19 & 65.0 & 61.0 & 4.0 & 35.0 & 11.0 \\
FS 1 & 100 & 93.9 & 6.1 & 0.0 & 12.6 \\
FS 2 & 71.0 & 70.8 & 0.1 & 29.0 & 12.5 \\
FS 3 & 100 & 91.3 & 8.8 & 0 & 12.8 \\
FS 4 & 100 & 89.0 & 11.0 & 0 & 10.2 \\
FS 5 & 90.0 & 90.0 & 0 & 10.0 & 12.6 \\
\hline
\end{tabular}


An important limiting aspect of enzymatic catalysis, as it is usually described [29], is the very high reaction times needed, in comparison with conventional chemical methods. In this sense, the results collected in Figure 5 showed that, in only two hours, the selective process was completely performed. Thus, in the first hour, the yields displayed a broad peak (RT = 53) corresponding to DG and/or TG, that remained without undergoing the ethanolysis reaction. In the second reaction hour, this peak practically disappeared. The peaks corresponding to FAEE and MG (RT $=17-25 \mathrm{~min})$ increased a lot in the second hour. These results were very similar in all the cases studied, employing eight different enzymatic extracts. Furthermore, the results obtained after two hours were pretty similar to those achieved after $24 \mathrm{~h}$ of reaction. This fact reinforced the possible application and profitability of this method from an industrial point of view.

a)

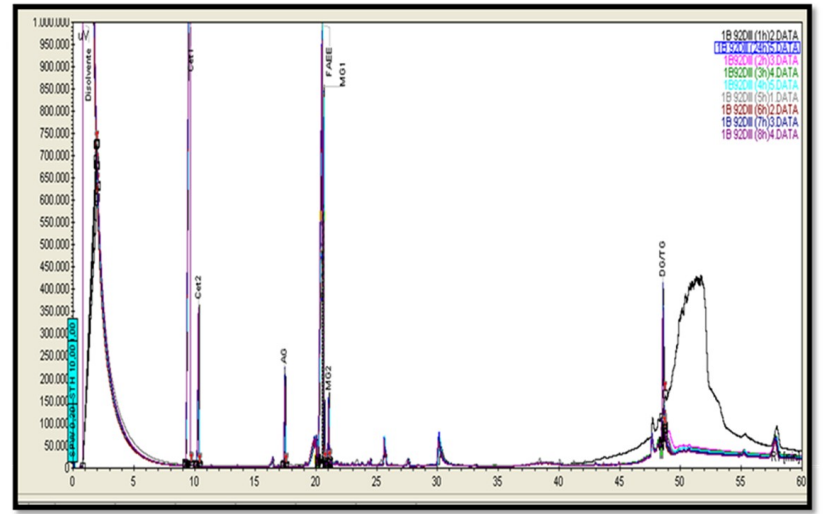

b)

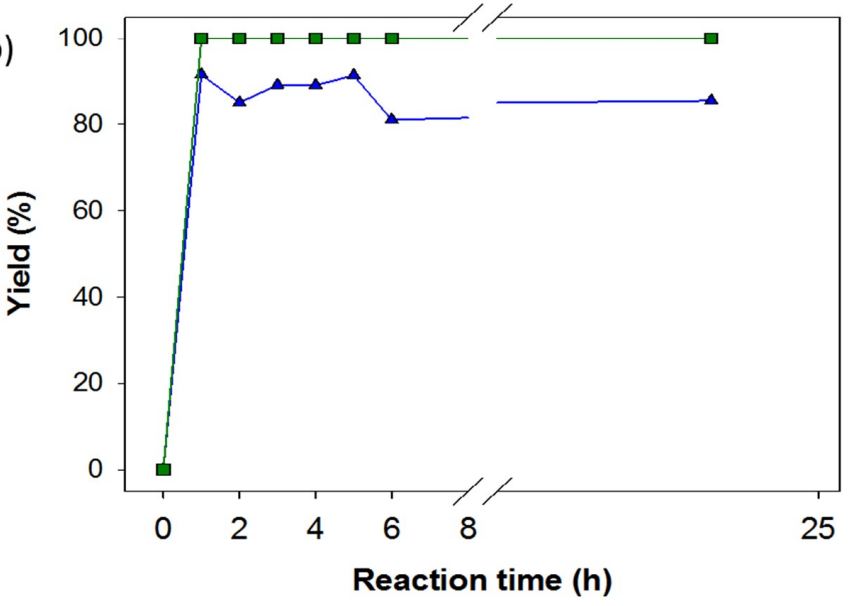

Figure 5. (a) Superimposed chromatograms corresponding to the ethanolysis reaction of sunflower oil, under standard conditions over the OS-8 wild microbial strain extract, at different reaction times. (b) Conversion (green squares) and selectivity (blue triangles) values obtained from these chromatograms.

In this respect, lipases exhibited several advantages in comparison with homogeneous alkali catalysts, such as high catalytic activity, moderate reaction conditions, ability to process vegetable oils containing a high degree of free fatty acid and water, diminishing the formation of soaps and emulsions, etc. [30]. However, sometimes it was too difficult to obtain complete conversion, which needed $48 \mathrm{~h}$ or more, although the yields near to $70 \%$ were obtained in relatively low reaction times, i.e., one or two hours. Obviously, this fact was due to the 1,3-selective nature of lipases which produce about a $30 \%$ of MG because of the impossibility of getting the alcoholysis of MG (Figure 1). We concluded, therefore, that the enzymatic catalysis is particularly suitable for obtaining Ecodiesel but is not applicable for producing conventional biodiesel that complies with EN 14214.

On the other hand, the presence of MG in the reaction medium had some effect on the flow properties, e.g., viscosity, in comparison with the conventional biodiesel (pure FAME). Therefore, 
its use as pure B100 in the ID engines is not completely advisable. However, the use of Ecodiesel as an additive for fossil diesel (e.g., at the typical B20, 20/80 biofuel/diesel ratio) seems to be adequate for diesel engines.

Furthermore, considering the use of lipases as possible enzymatic catalysts, another important factor to take into account must be the robustness of such enzyme, i.e., these enzymes must be reused in several successive processes, either free or immobilized [25-27]. In this sense, eight selected enzymatic extracts were subjected to successive ethanolysis reactions. In Figure 6, the catalytic performance of one of these enzymatic extracts (other results are not shown here) is plotted. As can be seen, the FS- 5 enzymatic extract exhibited similar conversion and selectivity values even after five reuses, indicating a very positive aspect for its industrial application.

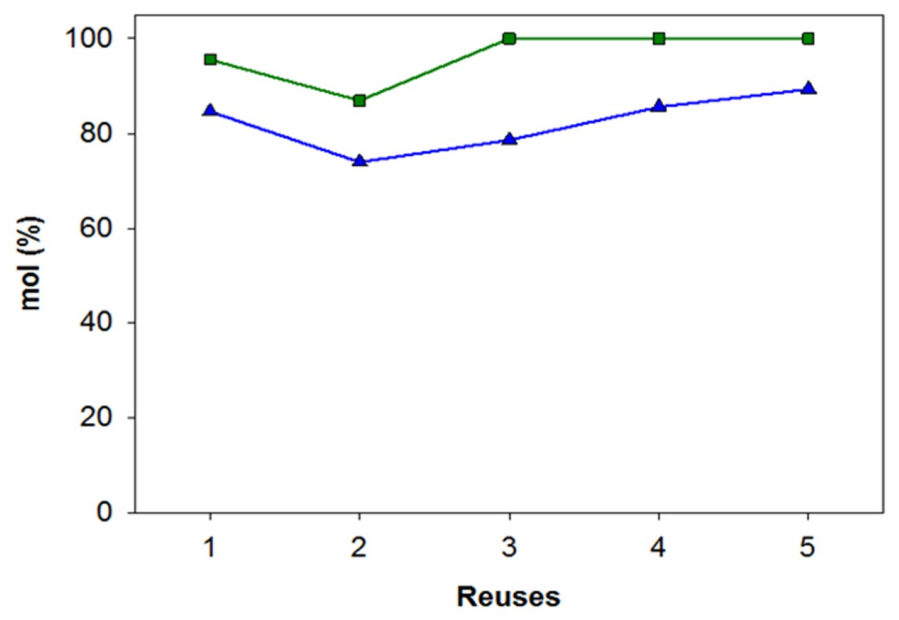

Figure 6. Catalytic performance obtained in successive reactions on FS-5 wild microbial strain extract in the sunflower oil ethanolysis reaction, under the same standard experimental conditions. Conversion (green squares) and selectivity (blue triangles).

According to recently new strains genera identified, some of the most efficient checked lipases from these wild microbial strains from vegetal oil samples were identified through a $16 \mathrm{RNRr}$ phylogenetic analysis. Among these microbial strains, the one belonging to the genus Terribacillus (OS-2), seems a promising option for biofuel production. However, in spite of getting high yields in the partial ethanolysis of the sunflower oil, the kinetic viscosity values of the Ecodiesel obtained were not better than those obtained with some samples here studied, e.g., OS-2 and OS-11 (Table 2), with which higher yield values were also obtained. Thus, the results here obtained are promising for making this option economically competitive in comparison to the conventional biodiesel production methods.

\section{Conclusions}

To improve a new methodology that integrates glycerol as monoacylglycerols, several microbial lipases from different wild microorganism strains, sampled in some lipophilic organisms, were evaluated as useful and inexpensive 1,3-selective biocatalysts in sunflower oil ethanolysis. These strains, which were previously selected and described [27], after isolation and cultivation, were applied to select those microbial strains which showed better enzymatic activity. Thus, an enzymatic material capable of performing Ecodiesel synthesis was obtained by a very simple procedure, consisting in the concentration of enzymatic extracts through dialysis followed by a lyophilization process from the corresponding strains. This Ecodiesel was obtained after very short reaction times (1-2 h) and under soft reaction conditions. Besides, a higher atomic yield was achieved (no glycerol was generated as a by-product), and the purification step of residual glycerol was not needed, indicating that Ecodiesel can be employed directly after its production. 
Furthermore, the freeze-dried bacterial cultures enzyme preparations can also be repeatedly re-used without losing efficiency, giving economic viability to the process. Thus, the results here obtained show the viability of a new paradigm, that is, the use of scarcely purified enzymatic extracts containing mixtures of several enzymes, instead of purified enzymes, which is currently the general procedure. In this sense, the presence of other enzymes should not affect the reaction, since these additional enzymes do not find in the reaction medium substrate molecules that allow their activity. However, only highly purified enzymes are commercially available, because these types of enzymes are required in biochemical research, although the high prices make them prohibitive for their application in fine chemical processes.

Author Contributions: This research article is part of the doctoral thesis of C.L., directed by professors D.L. and F.M.B., who in general conceived and designed the experiments and wrote the paper. An essential part of the microbiology experiments was developed with the invaluable contribution of E.D.S., however all coauthors made substantive intellectual contributions to this study, making substantial contributions to its conception and design, as well as to the acquisition, analysis, and interpretation of data. All of them were also involved in drafting and revising the manuscript, so that everyone gave final approval of the current version to be published in the journal Separations.

Funding: This research received no external funding.

Acknowledgments: This research was supported by the MEIC (Project ENE 2016-81013-R), Junta de Andalucía and FEDER funds (P11-TEP-7723), as well as MINECO project (MAT 2012-31127), that cover the costs to publish in open access.

Conflicts of Interest: The authors declare no conflict of interest.

\section{Abbreviations}

FAME fatty acids methyl esters, components of conventional biodiesel

DMC dimethyl carbonate

FAEE Fatty Acid Ethyl Ester

PPL porcine pancreatic lipase

FAE esters of fatty acids

MG monoglycerides or monoacylglycerols

DG diacylglycerols

TG triacylglycerols or triglycerides

GC gas chromatograph

RT retention times

p-NPP para-nitrophenyl palmitate

p-NP para-nitrophenol

OS Vegetable Oil Samples/Strains

FS Animal Fat Samples/Strains

B100 100\% Biofuel

\section{References}

1. Chen, D.; Liu, C.J. A Current Perspective on Catalysis for New Energy Technologies. ChemCatChem 2011, 3, 423-425. [CrossRef]

2. Wilson, C.; Grubler, A.; Bauer, N.; Krey, V.; Riahi, K. Future capacity growth of energy technologies: are scenarios consistent with historical evidence? Clim. Chang. 2013, 118, 381-395. [CrossRef]

3. Jong, S.; Antonissen, K.; Hoefnagels, R.; Lonza, L.; Wang, M.; Faaij, A.; Junginger, M. Life-cycle analysis of greenhouse gas emissions from renewable jet fuel production. Biotechnol. Biofuels 2017, 10, 64. [CrossRef] [PubMed]

4. Dhar, A.; Kevin, R.; Agarwal, A.K. Production of biodiesel from high-FFA neem oil and its performance, emission and combustion characterization in a single cylinder DICI engine. Fuel Process. Technol. 2012, 97, 118-129. [CrossRef] 
5. Ameen, M.; Azizan, M.T.; Yusup, S.; Ramli, A.; Yasir, M. Catalytic hydrodeoxygenation of triglycerides: An approach to clean diesel fuel production. Renewable and Sustainable. Energy Rev. 2017, 80, 1072-1088. [CrossRef]

6. Luna, D.; Calero, J.; Sancho, E.; Luna, C.; Posadillo, A.; Bautista, F.; Romero, A.; Berbel, J.; Verdugo, C. Technological challenges for the production of biodiesel in arid lands. J. Arid Environ. 2014, 102, 127-138. [CrossRef]

7. Calero, J.; Luna, D.; Sancho, E.D.; Luna, C.; Bautista, F.M.; Romero, A.A.; Posadillo, A.; Berbel, J.; Verdugo-Escamilla, C. An overview on glycerol-free processes for the production of renewable liquid biofuels, applicable in diesel engines. Renew. Sustain. Energy Rev. 2015, 42, 1437-1452. [CrossRef]

8. Ganesan, D.; Rajendran, A.; Thangavelu, V. An overview on the recent advances in the transesterification of vegetable oils for biodiesel production using chemical and biocatalysts. Rev. Environ. Sci. Bio/Technol. 2009, 8, 367. [CrossRef]

9. Ilham, Z.; Saka, S. Two-step supercritical dimethyl carbonate method for biodiesel production from Jatropha curcas oil. Bioresour. Technol. 2010, 101, 2735-2740. [CrossRef] [PubMed]

10. Ognjanovic, N.; Bezbradica, D.; Knezevic-Jugovic, Z. Enzymatic conversion of sunflower oil to biodiesel in a solvent-free system: Process optimization and the immobilized system stability. Bioresour. Technol. 2009, 100, 5146-5154. [CrossRef] [PubMed]

11. Kim, S.J.; Jung, S.M.; Park, Y.C.; Park, K. Lipase catalyzed transesterification of soybean oil using ethyl acetate, an alternative acyl acceptor. Biotechnol. Bioprocess Eng. 2007, 12, 441. [CrossRef]

12. Casas, A.; Ruiz, J.R.; Ramos, M.J.; Pérez, A. Effects of Triacetin on Biodiesel Quality. Energy Fuels 2010, 24, 4481-4489. [CrossRef]

13. Luna, D.; Bautista, F.M.; Caballero, V.; Campelo, J.M.; Marinas, J.M.; Romero, A.A. Method for Producing Biodiesel Using Porcine Pancreatic Lipase as an Enzymatic Catalyst. European Patent EP2050823A1, 5 September 2012.

14. Verdugo, C.; Luna, D.; Posadillo, A.; Sancho, E.D.; Rodríguez, S.; Bautista, F.; Luque, R.; Marinas, J.M.; Romero, A.A. Production of a new second generation biodiesel with a low-cost lipase derived from Thermomyces lanuginosus: Optimization by response surface methodology. Catal. Today 2011, 167, 107-112. [CrossRef]

15. Luna, C.; Sancho, E.; Luna, D.; Caballero, V.; Calero, J.; Posadillo, A.; Verdugo, C.; Bautista, F.M.; Romero, A.A. Biofuel that Keeps Glycerol as Monoglyceride by 1,3-Selective Ethanolysis with Pig Pancreatic Lipase Covalently Immobilized on $\mathrm{AlPO}_{4}$ Support. Energies 2013, 6, 3879-3900. [CrossRef]

16. Haseeb, A.; Sia, S.; Fazal, M.; Masjuki, H. Effect of temperature on tribological properties of palm biodiesel. Energy 2010, 35, 1460-1464. [CrossRef]

17. Wadumesthrige, K.; Ara, M.; Salley, S.O.; Ng, K.S. Investigation of Lubricity Characteristics of Biodiesel in Petroleum and Synthetic Fuel. Energy Fuels 2009, 23, 2229-2234. [CrossRef]

18. Xu, Y.; Wang, Q.; Hu, X.; Li, C.; Zhu, X. Characterization of the lubricity of bio-oil/diesel fuel blends by high frequency reciprocating test rig. Energy 2010, 35, 283-287. [CrossRef]

19. Cheenkachorn, K.; Fungtammasan, B. Biodiesel as an Additive for Diesohol. Int. J. Green Energy 2009, 6, 57-72. [CrossRef]

20. Heydari-Maleney, K.; Taghizadeh-Alisaraei, A.; Ghobadian, B.; Abbaszadeh-Mayvan, A. Analyzing and evaluation of carbon nanotubes additives to diesohol-B2 fuels on performance and emission of diesel engines. Fuel 2017, 196, 110-123. [CrossRef]

21. Celikten, I. The Effect of Biodiesel, Ethanol and Diesel Fuel Blends on The Performance and Exhaust Emissions in A DI Diesel Engine. Gazi Univ. J. Sci. 2011, 24, 341-345.

22. Yilmaz, N.; Vigil, F.M.; Donaldson, A.B.; Darabseh, T. Investigation of CI engine emissions in biodiesel-ethanol-diesel blends as a function of ethanol concentration. Fuel 2014, 115, 790-793. [CrossRef]

23. Kowalewicz, A. Eco-Diesel Engine Fuelled with Rapeseed Oil Methyl Ester and Ethanol. Part 2: Comparison of Emissions and Efficiency for Two Base Fuels: Diesel Fuel and Ester. Proc. Inst. Mech. Eng. D J. Autom. Eng. 2006, 220, 1275-1282. [CrossRef]

24. Moayedallaie, S.; Mirzaei, M. Paterson, Bread improvers: Comparison of a range of lipases with a traditional emulsifier. J. Food Chem. 2010, 122, 495-499. [CrossRef] 
25. Luna, C.; Verdugo, C.; Sancho, E.D.; Luna, D.; Calero, J.; Posadillo, A.; Bautista, F.M.; Romero, A.A. Production of a biodiesel-like biofuel without glycerol generation, by using Novozym 435, an immobilized Candida antarctica lipase. Bioresour. Bioprocess. 2014, 1, 11. [CrossRef]

26. Luna, C.; Verdugo, C.; Sancho, E.D.; Luna, D.; Calero, J.; Posadillo, A.; Bautista, F.M.; Romero, A.A. Biocatalytic Behaviour of Immobilized Rhizopus oryzae Lipase in the 1,3-Selective Ethanolysis of Sunflower Oil to Obtain a Biofuel Similar to Biodiesel. Molecules 2014, 19, 11419-11439. [CrossRef] [PubMed]

27. Escobar-Niño, A.; Luna, C.; Luna, D.; Marcos, A.T.; Cánovas, D.; Mellado, E. Selection and Characterization of Biofuel-Producing Environmental Bacteria Isolated from Vegetable Oil-Rich Wastes. PLoS ONE 2014, 9, e104063. [CrossRef] [PubMed]

28. Luna, C.; Luna, D.; Bautista, F.M.; Estevez, R.; Calero, J.; Posadillo, A.; Romero, A.A.; Sancho, E.D. Application of Enzymatic Extracts from a CALB Standard Strain as Biocatalyst within the Context of Conventional Biodiesel Production Optimization. Molecules 2017, 22, 2025. [CrossRef] [PubMed]

29. Stauffer, E.; Byron, D. Alternative Fuels in Fire Debris Analysis: Biodiesel Basics. J. Forensic Sci. 2007, 52, 371-379. [CrossRef] [PubMed]

30. Yara-Varón, E.; Joli, J.E.; Torres, M.; Sala, N.; Villorbina, G.; Méndez, J.J.; Canela-Garayoa, R. Solvent-free biocatalytic interesterification of acrylate derivatives. Catal. Today 2012, 196, 86-90. [CrossRef]

31. Macario, A.; Verri, F.; Diaz, U.; Corma, A.; Giordano, G. Pure silica nanoparticles for liposome/lipase system encapsulation: Application in biodiesel production. Catal. Today 2013, 204, 148-155. [CrossRef]

(C) 2018 by the authors. Licensee MDPI, Basel, Switzerland. This article is an open access article distributed under the terms and conditions of the Creative Commons Attribution (CC BY) license (http://creativecommons.org/licenses/by/4.0/). 